\title{
The Use of the Internet by Islamic Social Movements in Collective Action: The Case of Justice and Charity
}

\author{
Mohamed Ben Moussa \\ Concordia University, Montreal, Canada
}

\begin{abstract}
The article addresses the use of the internet by Islamic social movement organizations (SMOs), focusing on the case of Justice and Charity (JC), the biggest opposition political group in Morocco. It examines the extent to which the SMO exploits the potential of the medium in collective action, and the implications of this use for the SMO's capacity to advance its cause and resist state repression. Drawing on social movement and radical democracy theories, the study highlights the implications of the internet for collective identity-building in the political project of the Islamic SMO. The article argues that while JC draws extensively on the internet to enhance collective identity-construction and build an antagonistic public sphere, it fails to benefit from the potential of the medium to promote gender equality and genuine participative communication, and to build an agonistic political sphere.
\end{abstract}

Keywords: activism, internet, Islamic movement, radical democracy, social movement theory

The Arab world is witnessing unprecedented popular upheavals against despotism and dictatorship. During these events, the actual role of Islamic-oriented groups in the future of these countries has once again come under scrutiny. In fact, commentators have long noted that religion plays a prominent role in the Arab Westminster Papers in Communication and Culture (C) 2011 (University of Westminster, London), Vol. 8(2): 154-177. ISSN 1744-6708 (Print); 1744-6716 (Online) 
public sphere (Anderson, 1999; Eickelman and Anderson, 2003). Moataz Fattah, for instance, contends that 'where democracy does emerge in the Muslim world, it is likely to have a strong religious component' $(2006,126)$.

As far as Morocco is concerned, and since its independence in 1956, the country's political opposition has been strongly dominated by parties and groups that are leftist oriented, such as the Socialist Union of the Popular Forces Party and the Progress and Socialism Party. After participating in consecutive governments since 1998, traditional opposition parties lost much of their leverage as they are increasingly seen as 'selfserving "mediators" between the political elite and the real wielder of power', that is the king (Cavatorta, 2006, 208). As a consequence, Islamic-oriented political organizations, mainly the Justice and Charity group, the Unity and Reconstruction group, and the Justice and Development political party have emerged as the main opposition groups in Morocco.

Moreover, commentators have argued that Islamic movements in general have benefited enormously from alternative media, particularly Information and Communication Technologies (ICTs), in their efforts to advance their causes and intervene in local and global public spheres (Anderson, 1999; 2003; Bunt, 2003; 2005; Hoff, 2005; Ibahrine, 2007; Kort, 2005). These studies have addressed the impact of online communication and networks on the public sphere and religious discourse in these countries, and their role in reshaping struggles over the control of religious and political legitimacy. While important, this body of literature has remained predominantly descriptive, dealing mainly with the religious discourse circulated through these platforms at the expense of examining ways in which the internet, as a technology and political medium, contributes to the transformation of 'Muslim' public spheres. Furthermore, the bulk of analyses on collective action in Muslim societies have generally remained 'isolated from the plethora of theoretical and conceptual developments that have emerged from research on social movements' contentious politics' (Wiktorowicz, 2004, 3).

This article aims to address these lacunae in research dealing with the implications of the internet for social movements, in general, and within the context of Muslim majority societies, in particular. The article concentrates on the 
case of 'al-adl wal-Ihsane' (Justice and Charity), the largest and most important oppositional Islamic-oriented group in Morocco, and its use of the internet as a collective action tool. For many observers, the organization has become a key player in the political scene of the country, and would perhaps easily win elections if it was to participate in mainstream politics (Cavatorta, 2005; Weitzman, 2003). The group advocates the non-violent transformation of society, and its activities range from public demonstrations and protests to organizing spiritual and welfare services. Though the organization has been outlawed since its foundation, the JC had been relatively tolerated by the state. In recent years, however, police and judicial repression against it significantly intensified. The state banned all the groups' print publications, and repeatedly, though unsuccessfully, tried to block access to its websites. Thus, the JC offers an interesting case for examining the use of the internet in political activism and resistance within Muslim majority societies.

This case is all the more interesting to study because the JC was one of the first groups in the country to effectively appropriate the internet for political purposes. Its website first started in 2000 and, since then, the group managed to launch many versions, the most recent one in 2009. In 2000, the SMO launched a website (wwww.yassine.net) to publish an open letter addressed by its leader Abdessalam Yassine to King Mohammed VI. The letter criticized Hassan II's reign, ${ }^{1}$ and urged the young king to redistribute his father's wealth. This was the first clear example of the use of the internet for political purposes in the country, and some commentators even suggested that the case set the scene for the political appropriation of the internet in Morocco (Ibrahine, 2005). According to Alexa.com, 2 the JC's website is ranked 236th in Morocco, which makes it the most visited political site in the country. Moreover, the JC women's section, Sisters of Afterlife, was one of the first women groups to set up a website for purposes of activism, and for many years the platform remained the only website addressing women that was regularly updated.

Using two content analysis-based methods, namely feature and frame analyses, the article highlights structural and frame dimensions of the SMO's websites, and 
sheds light on the extent to which the potential of the internet is exploited by the Islamic organization in mobilization and activism. In particular, the article will attempt to answer the following three main questions:

Q1: To what extent does the JC organization exploit the potential of the internet for collective action?

Q2: To what extent can it be said that the internet has enhanced the capacity of JC to advance its cause and challenge state oppression?

Q3: To what extent can the JC's appropriation of the internet contribute to building an agonistic public sphere in the context of Morocco?

Drawing on social movement and radical democracy theories, the article highlights various forms of articulation between collective identity transformation and social justice in the political project of the Islamic-oriented SMO. The article argues that while JC succeeds in appropriating the internet to enhance collective identity-construction and build an antagonistic public sphere, it fails to benefit from the potential of the medium to promote gender equality and participative communication, and to build an agonistic political sphere.

\section{The Justice and Charity SMO}

The JC was founded in 1984 by its charismatic leader Abdessalam Yassine. From the early 1970s, Yassine publicly challenged King Hassan II, which brought him long periods in prison and under house arrest. The exact number of members of the group is not known, but it is estimated to be between 50,000 and 600,000 (Cavatorta, 2006). The JC combines charitable activities within the poorest segments in society, advocacy for its Sufi-based non-violent Islamic societal and political project of a democratic Islamic state, and open opposition to the monarchy. The SMO asserts that it strives to establish:

a political system based on Islam, where 'shura' or consultation and justice constitute its basis, and where charity ${ }^{3}$ its soul. Public participation, 
political pluralism, the supremacy of institutions, and the rule of law are the guarantees for the system's continuation, while discussion and the consultation of people are its tools. ${ }^{4}$

Moreover, the SMO refuses to participate in elections, believing that doing so in a political context that does not guarantee full conditions for free and independent actions would only lead to half-way compromises with the real holder of power, that is, the king. Thus, despite various forms of pressure on the group and its leaders to agree to join the 'official' political process, the movement has resisted so far and preferred to continue its political action through predication (Cavatorta, $2005,213)$, that is, calling upon the members of society, through various peaceful means, including preaching, education, giving a good example and charitable work, to join in the group's societal project. Marina Ottaway and Meredith Riley (2006: 14-15) describe JC as:

a complex and at times bewildering organization. In part, it is an organization in the mould of Morocco's numerous traditional Sufi brotherhoods, nonviolent and suffused with a strong current of mysticism, including a belief in the importance of dreams. In part, it is a very political movement, with some of its leaders prone to using the radical language of dependency theory and Third World revolution.

The JC relies heavily on the internet as a tool of communication and mobilization and its members use a large number of online tools such as video sharing platforms, blogs and personal websites. The JC's Arabic website and its French version remain, however, the only official media outlets for the group, wherein the leaders' opinions and the group's communiqués are published. ${ }^{5}$ The websites provide information about the SMO, its objectives as well as its leader's reflections and writings. They also feature daily news about the group, Morocco and the Islamic world, analysis and opinion contributions from member activists, 
in addition to text and multimedia content that can be read, viewed or listened to online, or downloaded for offline use and sharing.

The French and Arabic versions of the website share the same URL address, and users can switch to either of them through a link on the websites' homepages. Using both Arabic and French is not unique to the group insofar as the majority of political groups, governmental departments and business companies in Morocco follow the same strategy in a country where Arabic is the official language, but where French is dominant among political and economic elites. The JC's founder is fluent in both languages and published many books in both of them. In addition to its role in addressing actual and potential francophone members in Morocco, the use of French is also a strategy to mobilize the group's strong constituency in the diaspora, particularly in France and Belgium where there are large Moroccan communities. Despite sharing address name, and some design features, a preliminary examination of the Arabic and French websites show that they differ on many levels, which explains our decision to study them as separate websites.

As to the third website, it belongs to the JC's women chapter, Sisters of Afterlife that was founded by Nadia Yassine, the outspoken daughter of the SMO's leader. The website was launched in 2005 and has remained, until recently, one of the rare political sites addressing women in the country. ${ }^{6}$ In the framework of JC's 'reIslamization' project, the Sisters of Afterlife SMO and its 'communication tool' aim to address the 'dangerous deterioration of the status of women along[side] the deterioration of the [Muslim community]'.

\section{The Implications of the Internet for Social Movements}

Since the Seattle protests against the World Trade Organization (WTO) in 1999, commentators have highlighted a large number of examples in which the internet played a key role in enhancing social movements' collective action capabilities, especially to coordinate actions and widely distribute counter-hegemonic discourses (Diani, 2001; Downey and Fenton, 2003; Downing, 2001; Kahn and Kellner, 2004; Van Aelst and Walgrave, 2004). Kelly Garrett (2006, 204), for instance, identifies within the literature three types of 'mechanisms' linking the 
technology to social movements, namely 'reduction of participation costs, promotion of collective identity and creation of community'. Similarly, summarizing existing literature on the subject, Laura Stein $(2009,757)$ pinpoints the internet's six functions for social movements: (a) providing information; (b) assisting action and mobilization; (c) promoting interaction and dialogue; (d) making lateral linkages; (e) serving as an outlet for creative expression; and (f) promoting fundraising and resource generation. Nevertheless, many commentators are sceptical about the internet's capacity to deeply transform collective action politics and social movements. The main issue that the literature addresses, therefore, is 'whether these communication practices merely reduce the costs or increase the efficiencies of political action, or whether they change the political game itself' (Bennett, 2003, 144).

\section{Social Movement Theory and Radical Democracy}

The present article draws on two key conceptual frameworks, namely social movement theory and radical democracy theory. Social movement theory offers a useful conceptual framework in which Islamic-oriented movements and their communication practices can be studied and better understood. David Snow $(2004,6)$ organizes existing definitions of social movements around five main axes: (a) 'collective or joint action'; (b) 'change-oriented goals or claims'; (c) an 'extra- or non-institutional collective action'; (d) a 'degree of organization'; and (e) and a 'degree of temporal continuity'. This definition offers a deeper insight into Islamic-oriented movements and their use of the internet. First, social movements are a form of contentious and oppositional collective action aimed at social, political and/or cultural change. Second, the definition of social movements encompasses both institutionalized and non-institutionalized forms of activism, which helps account for highly decentralized and horizontal modes of communication that distinguishes many forms of online-based activism. Third, social movements cannot be reduced to a single group because they are constellations of SMOs and individuals that are loosely connected, but that share collective identity and objectives. 
Moreover, with their focus on self-transformation and identity, Islamicoriented movements are typical examples of new social movements (NSMs). Unlike previous types of movements, such as trade unions, which focused mainly on social injustices, new social movements intervene in the public sphere to challenge dominant discourses on issues of identity and lifestyle (Habermas, 1981). The distinctiveness of Islamic movements' agenda, however, lies in their simultaneous focus on the transformation of identity and lifestyle at the individual and collective levels, as well as on achieving social and political justice. As Manuel Castells (2004: 17) explains:

for all the efforts of exegesis to root Islamic identity in history and the holy texts, Islamists proceeded, for the sake of social resistance and political insurgency, with a reconstruction of cultural identity that is in fact hypermodern.... Indeed, the explosion of Islamic movements seems to be related to both the disruption of traditional societies ... and to the failure of the nation-state, created by nationalist movements, to accomplish modernization, develop the economy, and/or to distribute the benefits of economic growth among the population at large.

Social movement theory also offers a useful interpretation of the notion of mobilization that can help us better understand the implications of the internet for collective action. In particular, the concept of 'micro-mobilization' allows us to appreciate 'the collaborative work individuals do on behalf of a social movement or social movement organization to muster, ready, coordinate, use, and reproduce material resources, labor, and ideas for collective action' (Hunt and Benford, 2004, 483).

This article also draws on an alternative conceptualization of the public sphere based on 'radical democracy' theory (Laclau and Mouffe, 1985; Mouffe, 1999), most specifically the notion of an 'agonistic' public sphere. This model views politics as intrinsically conflictual and not consensual. But it also stresses the importance of pluralism in which political actors recognize the legitimacy of their 
opponents. Accepting difference is essential because it prevents agonistic politics turning into antagonism (Mouffe, 1999). Commentators have argued that the internet's main contribution to democracy has been through its promotion of agonistic politics (Atton, 2004; Dahlberg and Siapera, 2007; Khan and Kellner, 2007). Within this perspective, the public sphere is understood as the site of 'agonistic politics associated with power and exclusion' (Dahlberg and Siapera, 2007, 133).

\section{Methods}

Two content analysis-based methods have been used in the study, namely framing analysis and feature analysis. First, by appreciating the link between social movements' frames and mobilization, framing analysis provides a basis for bridging the gap between the ideational and symbolic dimensions of collective action and direct forms of mobilization. Frames can be defined as 'schemata of interpretation that enable individuals to locate, perceive, identify, and label occurrences within their life space and the world at large' (quoted in Snow et al., 1986, 464). Commentators have maintained that social movements' framing efforts are the foundation of collective action as a whole, because recognizing particuar situations as unjust precedes the collective action that strives to address the injustice (McAdam, 1982, 51). Framing analysis has one other key contribution - namely, its capacity to demonstrate how individuals become involved in collective action, thus highlighting the interplay between agency and structure in the development and action of social movements (Williams, 2004).

Second, feature analysis is a methodology based on both quantitative and qualitative content analysis. It is a research tool that allows for the systematic analysis of websites without overlooking non-quantifiable dimensions, such as design and efficiency. The advantage of using this method, as Roman Gerodimos $(2008,972)$ points out, is that it can produce 'formal and rigorous data that is comparable across cases ... thus avoiding common pitfalls such as informal or impressionistic assessments'. For the purpose of this study, four main web features are analysed: (1) freshness or updating of websites; (2) interactivity; (3) 
networking; and (4) direct mobilization. ${ }^{7}$ Each of these levels is measured using a set of codes provided in full details below.

The Arabic and French websites' homepages, in addition to the Sisters of Afterlife's website, ${ }^{8}$ were observed and downloaded over a period of one month between 15 November and 15 December 2008. This timeframe was specifically chosen because it fell within a period when the Moroccan state stepped up its repression of the JC group.

As mentioned before, the JC has pioneered the use of the internet in collective action in the context of Morocco. The three studied websites are the main and official communication tools used by the group at a time when the state has banned all its print publications, which provides a very good example of how a political group can benefit from the internet to challenge a media siege and political repression. The websites also offer important venues through which the study will try to illustrate the extent to which the JC appropriates the potential of the web for collective action purposes in general, and how this potential is customized to address various categories of potential users (users in Morocco versus those in diaspora, Arabophone versus francophone, men versus women, among others). This is important because it helps us to better understand how the internet's potential for collective action is equally contingent on technological features and users' practices and worldview (for instance their stance on patriarchy), through which this potential is mediated.

\section{Frame analysis}

Jenny Kitzinger argues that framing analysis can be carried out with 'varying degrees of methodological rigour, sophistication or sensitivity' $(2007,140)$. She proposes mixing various methods to analyse multiple aspects of texts and to identify key cues making up the frames, such as 'images, language, labels and definitions, offered explanations, assigned responsibility, proposed solutions, contextualization and links, historical associations metaphors, [and] emotional appeals' (2007, 141-2) among others. 
Thus, a thematic analysis was performed on textual items generated by the websites to identify the most salient issues they tackle. To identify the key frames in the data, the paper draws on William Gamson's (1992) distinction between three principal components of collective action frames, namely: (1) injustice, (2) identity and (3) agency frames. The injustice frame refers to the 'moral indignation' that is not 'merely a cognitive or intellectual judgment about what is equitable ... [because it] requires a consciousness of motivated human actors who carry some of the onus for bringing about harm and suffering'. The identity frame refers to 'the process of defining this "we," typically in opposition to some "they" who have different interests or values' (ibid., 7). As to the agency frame, it refers to the 'consciousness that it is possible to alter conditions or policies through collective action'. Agency frames 'empower people by defining as potential agents of their own history' (ibid., 7).

The themes obtained, then, were grouped into the three types of core frames identified above. The codes obtained from a pilot study on a third of the data were applied afterwards to the rest of the data. The fact that these codes were only slightly modified at this stage demonstrates their reliability. The thematic components of the three core frames found on the studied websites can be summarized as follows:

\section{Injustice frames}

- News on the Gaza blockade and statements of solidarity with the Palestinians.

- News on police violence against JC activists, arrests, trials, prison terms.

- Social injustice and critique of unequal distribution of resources and income in Morocco.

- Lack of fair elections and real representation, and governance issues.

\section{Identity frames}

- Understanding 'Islamic' identity versus a secular one.

- Reinterpretation of religious texts, teachings and jurisprudence. 
- History of early Muslim communities.

- Essence of Islamic education and upbringing.

- Role of women in society and in the household.

\section{Agency frames}

- Action calendar for upcoming strikes, street protests, sit-ins, other direct action events.

- Reports and news on protests, sit-ins or other forms of action in which the JC members participated.

Analysis has demonstrated (see Table 1) that injustice frames are predominant on the Arabic and French websites, while identity frames occupies second position. Besides, analysis shows that agency frames are limited on all the websites, with the JC French website the only one to contain a significant number of items calling for various forms of action. Equally important, analysis clearly shows that the website of the women's chapter focuses almost exclusively on identity frames.

The results prove Robert Benford and David Snow $(2000,615)$ right when they criticize the claim that all social movement frames are injustice ones. However, Benford and Snow go on to maintain that, in the case of religious and identity groups: 'it is questionable whether a well elaborated collective action frame need include an injustice component' (ibid., 615). This statement does not stand much scrutiny since the analysis shows that injustice frames constitute the majority of all frames found on Arabic and French websites. In fact, a significant part of all the textual items found on the websites deal with the victimhood of the SMO that had been subject to a nation-wide campaign against its members, affiliated associations and local leaders by Moroccan authorities. Thus, a large number of items deal with the news of members arrested, tortured or sentenced to jail by the state, the illegal closure of offices and homes, the continued infringement on the rights of members during 'kangaroo' trials, among others.

Despite being religion-oriented, JC draws heavily on human rights culture and discourse to frame the violation of the basic rights of the groups and its members, 
particularly the right of expression and gathering. Commemorating International Human Rights Day, one article, for instance, denounced the continuing infringement of the JC members' human rights by Moroccan state, in addition to the violation of the rights of other political groups in society. The article denounces the 'black record of human rights violations in Morocco, which grew worse this year with the brutal attacks on the town of Sidi Ifni by state security apparatuses, the continual war against free media and continual siege imposed on the Justice and Charity'. ${ }^{9}$ The use of the human rights discourse allows the JC to present itself as a modern political, albeit religious-oriented, group, and to appeal to civil society groups at the national and international levels to honour their mission and values and to support the group in its plight. The article simultaneously calls for 'all those who are concerned by the present and future of Morocco to denounce the violations against the JC', while it condemns 'the silence of the media, and the idle passivity of the political and civil societies on the JC members' sufferings'.

In addition to injustice frames, identity frames deal with a wide range of issues, such as Islamic teachings on the ethics of personal relationships between people in private and public life, 'Islamic' education and upbringing of children, alternative conceptualization of Islamic jurisprudence, celebration of religious festivals and obituaries, among others. The JC declares that its project is not primarily a political one: politics is 'part of our mission and not all of it'. The two primary objectives of the SMO are the 'renewal of faith and the renewal of religion', and for this reason they 'focus on education in our project' because education 'transforms people, frees their will $\ldots$ and mind $\ldots$ and through education people become effective in history'. ${ }^{10}$ Accordingly, one of the main goals of the websites is to provide members and Muslims in general with 'Islamic' interpretations of social activities to enable them to achieve not only justice, but also charity (see above for an explanation of this term). A case in point is an article on 'family happiness' that explores how Islam views a perfect family life. The article describes how worshipping God at home can be done in harmony with other activities that connect husband to wife, parents to children, and children to their parents. Praying is not an act isolated from other activities, but should be integrated in the spatial 
and temporal activities of the family ${ }^{11}$ and society in general to achieve a perfect relationship with God, with the other and with oneself.

Although the French website shares with the Arabic website many types of content, it is more oriented towards users who either are not Muslims or are Muslims but live in the diaspora. One folder, absent from the Arabic website, is entitled 'Discover Islam' and presents basic information on the religion, its rituals and philosophy. The website's focus on ' $d a^{\prime} w a$ ' or 'predication' is illustrated by the posting of this passage from Yassine's Islamizing Modernity addressing potential individuals interested in Islam:

How to initiate myself into Islam if I am the product of a secular society that is indifferent to issues of faith but I feel drawn to Islam and want to try, perhaps, practicing it? Pay attention, dear soul, to doubtful meetings. In the mosque, particularly the mosques in diasporic Islam, you will meet erudite and expert people who will talk to you about laws and books in a dry way devoid of their substance. ${ }^{12}$

The objective of this passage is not just to help non-Muslims convert into Islam, but also to draw a distinction between the type of Islam preached by mosque imams, who are for the most part nominated by the state and advocate a type of Islam that emphasizes jurisprudence and rituals, and the type of Islam advocated by the JC that focuses on the spiritual and philosophical dimension of religion and that addresses all aspects of life and culture at the individual and collective levels.

While in general it is possible to distinguish between identity and injustice frames, in many cases both frames are intertwined insofar as the victimization of the organization is understood to be emanating from its societal and cultural project aiming at the 're-Islamization' of identity at the individual and collective levels. Similarly, existing social and economic injustices are seen to require not only new policies and plans, but specifically the transformation of the entire value system upon which society is structured. Linking injustice frames to identity ones often draws on historical and allegorical comparisons and parallelism, as is the 
case with an article on the events of Sidi Ifni, ${ }^{13}$ which led to the imprisonment of members of the JC, among many other groups' activists. The crackdown on the residents of the town by Moroccan police, for instance, is compared to Yazid Bin Muawiya's savage crashing of rebellions in the holy cities of Mecca and Medina. ${ }^{14}$ The parallelism between the two events exploits powerful symbols and images in collective memory and culture, which not only magnifies the scale of injustice but also, and more importantly, distinguishes between the 'us', the true Muslims, and the 'them', the Moroccan regime that is denied any religious or political legitimacy. The rhetorical and symbolic importance and weight of the interplay between identity and injustice frames transcend their sheer frequency on the websites. Kitzinger notes that frames are often condensed in powerful symbols or images, and that 'the whole frame does not have to be spelt out in every detail in order to invite readers/viewers to recognize and place the issue within the frame' (2007, 141).

Indeed, identity and injustice themes on the studied websites are usually intertwined, with injustice frames subtly running through different themes, from celebration of important religious days to obituaries of fellow members. An example of this is the large number of obituaries posted on the website of a founding member of the organization and a companion of Abdessalam Yassine, the late Mohammed Sulaymani. But while these obituaries highlighted the life and achievements of the dead leader, they were also an opportunity to reflect on the history of the movement, its distinction and the hardships it has been facing since its establishment, which run parallel to the life of the dead leader. Besides, many of these obituaries compared the experience of the SMO to that of the early Muslim community that was persecuted in Mecca. One poem even drew a parallel between Yassine and Sulaymani's prison experience and the experiences of Prophet Muhammad and his companion Abu Baker Seddik ${ }^{15}$ during the early days of Islam.

Compared to injustice and identity frames, however, agency frames are rare or absent in the JC websites. At best, agency frames focus on the need of selftransformation at the individual level, and resisting the state's attempt to break down the SMO. The French website provides some few exceptions, since it 
constantly features flash photo slides of imprisoned members, accompanied with messages calling for their freedom. The distinctness of the French website at this level can be attributed to the nature of the targeted users, as it aims to mobilize adherents and sympathizers in European countries, who can often demonstrate to denounce the state campaign, and to draw the attention of international NGOs that often criticize the country's poor records on human rights issues.

As far as the website of the women's chapter is concerned, identity frames in it focus predominantly on the role of women as mothers and wives, particularly in providing an 'Islamic' education to children, their duties towards their families, the ethics of relationships in society, and 'inspiring' stories from the history of women in Islam. The dominance of this latter frame contrasts with the declared objectives ${ }^{16}$ of the website, which seeks to contribute to the JC's societal and universal mission to redress the 'illnesses' that have befallen Islamic community or ummah by 'renewing its Islam'.

The orientation of the website is well reflected in the folders found on the main menu bar directing users into the content. There are six folders entitled: 'Who we are'; 'Our vision'; 'Divine issues'; 'True women'; 'For the family'; 'Issues'; 'Flashes'; 'Communication'; 'Services'. The section entitled 'True women' features articles on female figures in the Islamic history, whose lives illustrate how women in a 'real' Muslim society should behave. While some of these articles highlight the role of these women in the public sphere, mainly as religious scholars and politicians, the majority focus on the rights and obligations of women as wives and mothers, in addition to their self-discipline in order to become pious persons. Similarly, the website has a forum where female members can discuss and share their views on various issues. The forum contains nine sections or folders that members can access either to participate in ongoing discussions or start new issues within these sections: (1) Come worship for one hour; (2) Issues and events; (3) Adam and Eve; (4) Our children; (5) Oasis for youth; (6) Your health; (7) The best companion; (8) Creative expression; (9) From here and there, which is the sole section in which members contribute in French and not Arabic, as is the case with the others. Thus, except for the second section dealing with news and issues related to the JC, 
Morocco and the world in general, all the others deal either with purely religious issues, or with social issues through an 'Islamic' perspective, mainly gender relationships, education of children, family and social life. The sections on 'Creative expression' features classic poetry, cartoon and drawings that heavily draw on religious discourse and themes. The last section contains all issues in the other sections as it is meant to be a platform where members from among Moroccan diaspora can participate in the forum.

Thus, in the framework of the JC's re-Islamization project, the Sisters of Afterlife and their online 'communication tool' aim to address the 'dangerous deterioration in the status of women along with the deterioration of the Ummah' or global Muslim community. As such, the objective of the women's chapter and its website is to 'transcend shallow handling of the gender issue' by transforming the role of women from mere caregivers to individuals who are actively involved in the wider issues that concern society and Islamic community worldwide. In fact, women play a prominent role in the JC's project of the 're-Islamization' of society, a project that targets children education and family life, as well as the political system of the country. Nevertheless, the dominant frames in the website reflect a failure to engage seriously with cultural and societal discourses and orders that prevent women from fulfilling their role not only as mothers and wives but also as citizens. Tayeb Belghazi $(2003,1)$ aptly summarizes this project in the following terms:

despite the contradictions that obtain between the radical and the moderate wings of Islamism, we can talk of an Islamist community that partakes in a shared attitude towards the traditional patriarchal family considering it as the most important element of Morocco's Islamic identity.

The centrality of the question of identity to the JC proves how this group, as is the case with Islamic social movement, is part of new social movements in the country and region. A number of commentators, however, have questioned any attempt to establish a categorical distinction between 'old' and 'new', or 'identity' 
and 'strategy' oriented movements, claiming that the majority of movements 'combine both instrumental and expressive action' (Taylor and Van Dyke, 2004, 266-7). This is particularly true in the developing world context, where identityoriented collective action is usually rooted in political, economic and social injustices. The case of the JC illustrates this idea, as analysis shows that injustice frames constitute a prominent part of those communicated on the SMO's websites. To complement framing analysis, feature analysis was conducted to examine the structural aspects proper to the internet as a technology and that distinguish it as a political medium.

\section{Feature Analysis}

Website Freshness

Studying the freshness of a website, that is, the degree and frequency of its updatedness, provides a valuable insight into the potential of the website as an information provider, and its ability not only to attract users but also, and more significantly, to 'encourage them to return' (Gibson and Ward, 2000, 5). To examine the freshness of the studied websites, textual content was coded for the number of new items added and the frequency of updating during the month of December 2008. This was measured using three codes: daily updating, weekly updating and longer than weekly updating. Analysis has revealed important variations between the websites studied, with the JC Arabic website the most frequently updated and the website of the women's chapter the least updated (see Table 2). These results provide an insight into the importance accorded to each platform by the JC SMO, and the role these platforms play in the SMO's collective action strategy, in general. On the one hand, the fact that the JC Arabic website is the most frequently updated platform is normal given that it is considered the main and official website of the SMO, and it addresses actual and potential constituencies through the language they use and understand best. The low frequency of updating of the website of the women's chapter, however, shows that it receives much less attention than the others, which may betray unbalanced gender relations inside the organization. 


\section{Website Interactivity}

Interactivity has widely been described in the literature as 'a key variable for studying the uses and effects of new media technologies' (Sundar et al., 2003, 32). Broadly speaking, two types of interactivity are identified, namely user-totechnology or medium and user-to-user (Lee, 2000; Liu, 2003; Stromer-Galley, 2000, 2004; Sundar et al., 2003). The first view defines interactivity in terms of the technological features of the medium, 'such as hyperlinking, activating media downloads, filling in feedback forms, and playing online games' (Warnick, 2006, 69). The second view claims that interactivity occurs only when messages sustain reciprocal exchanges between communicators' (Warnick, 2006, 69), via such means as emails, forums and chat-rooms.

For the purpose of this research, three types of interactivity are identified and used as a guide for a coding system to analyse interactivity function on the studied websites, namely user-to-document, user-to-system and user-to-user or interpersonal interactivity. This categorization covers the major aspects of interactivity, particularly within new media studies (Carpentier, 2002; McMillan, 2002; Rafaeli, 1988; Szuprowicz, 1995). These types of interactivity, Sally McMillan $(2002,209)$ argues, 'provide a basic framework for the investigation of the past, present, and future of interactivity'. Thus, user-to-document interactivity refers to users' interaction with documents and their creators, which involves 'both perceived interaction with content creators and actual creation of content' (ibid., 213). Three features were coded in this category: (a) comment on article; (b) submit content; (c) contact author. User-to-user interactivity deals with the 'ways that individuals interact with each other' (ibid., 209). Four features were coded in this category, namely (a) existence of a forum; (b) share article via email; (c) share article via social media; (d) synchronous chat. Finally, user-to-system interaction focuses on the ways that 'the human communicates directly with computers and other new media systems' (ibid., 218). This category was coded using ten features: (a) make us your homepage; (b) download content; (c) RSS; (d) website plan; (e) 
multimedia content; (f) search website; (g) opinion polls; (h) register online; (i) receive email newsletters; (j) contact webmaster. (See Tables 3 and 4)

As in the previous analyses, the JC Arabic website scores higher than the other two in the function of interactivity, while that of the women's chapter appears to be the least interactive of the three. These variations reflect some of the key communication functions each website performs and the objectives, intentional or not, behind setting them up. On the one hand, the JC Arabic website is the main online platform of the organization, since it is destined for the bulk of the SMO's adherents, particularly inside Morocco. Interactivity on it allows for a more participative and dynamic communication flow, thus boosting its potential for mobilization and collective identity-construction. Among the key interactive features on it are the forum where members discuss various issues, live broadcasting that allows users to attend virtually meetings and lectures given by the groups' leaders and ask them questions. The French website, on the other hand, addresses some of the SMO's followers in Europe who might not know much Arabic, as well as 'bystanders', including francophone Moroccans, and an international public, including Westerners who might be interested in learning more about the organization. One of its main functions, therefore, is not to mobilize adherents but to provide information. The low interactivity of the website of the JC women's chapter can be attributed to different causes, however. Since the main Arabic website of the organization is intended for men and women alike, women members are expected to use the interactive features on it if they wish. Nevertheless, weak interactivity on the website of the women's chapter reflects, as also evidenced by the website's framing analysis below, the stance of the JC towards gender relations, whereby women are relegated to secondary role inside the organization.

Equally important, results show that the three websites scored relatively high on user-to-user and user-to-system interactivity and very low on user-to-content interactivity. User-to-system interactivity features, such as the possibility to download or search for content, give users some control over communication, 
particularly by allowing them to customize the way they receive and consume content; while user-to-user interactivity permits users/members to communicate via email or a synchronous chat platform. The two types of interactivity reflect a strong lateral/horizontal communication flow, in addition to a restricted upward flow. This plays a direct role in enhancing the sense of belonging to the organization, intra-community bonding, and collective consciousness and identitybuilding. However, low user-to-content interactivity, especially the inability of users to comment on articles, betrays a control over the production of discourse on the websites. It is worth noting that only the French website allows users to comment on content, which can be interpreted as an effort to appeal to diasporic constituencies in various Western countries who are accustomed to higher levels of freedom of expression than inside Morocco. It can also be explained by a desire on the part of the organization to appear modern and pro-democracy, especially to international observers, such as scholars, journalists and NGOs.

\section{Networking}

Networks and networking have always been central to social movement structure and collective action. Often described as being 'networks of networks' (Diani and McAdam, 2003), social movements are generally based on a large and complex web of organizations, groups and individuals. Moreover, they form alliances with

diverse social actors, including SMOs, media and political parties, with whom they share common objectives, causes or ideological background. The networking potential of the internet is commonly associated with its hyperlink feature, one of the major characteristics of the internet (Downes and McMillan, 2000; Warnick, 2006). Analysis of networking was performed by counting the number of external links on the homepage and first-level pages, and coding them according to their types. Analysis has demonstrated that all the websites score low on networking. Indeed, on the three websites, there are only four permanent external links to websites that are all affiliated to the movement, namely the personal websites of JC's leader and Nadia Yassine, in addition to the website of the Sisters of Afterlife 
and the JC Forum website. Moreover, analysis has shown that there are no external links within any of the web pages we analysed.

In fact, although news articles and reports on the movement from national and international news outlets and NGOs are often quoted in length on the website, no direct links to their sources are provided. Hyperlinks 'can express meanings, they betray biases, they invite or suggest inferences, and sometimes they manipulate the reader' (Burbules and Callister, 2000, 84). As such, the networking potential of the internet is used primarily on the JC's websites to promote internal cohesion or 'bonding' at the expense of networking or 'bridging', to borrow Robert Putnam and Kristin Goss's concept (2002).

\section{Direct Mobilization}

The notion of 'mobilization' is central to social movement theory in the sense that it incorporates various processes in collective action, from access to material and non-material resources to the production of frames and symbols that delimit a movement's collective identity and field of action. In this section, 'mobilization' is used to refer to what Gamson (1992) calls 'affirmative action', that is, direct forms of mobilization and enlisting support, such as recruitment of new members, collection of funds and participation in offline and online protests and campaigns. To examine this function, eight codes have been used designating various online and offline forms of direct mobilization: (1) becoming a member or joining; (2) volunteering; (3) donating; (4) boycotting; (5) signing a petition; (6) email campaign; (7) urgent alerts; (8) action calendar. Analysis has been conducted by observing the studied websites for the absence or presence of these features, and coding them with either 0 (for absence) or 1 (for presence). (See Table 5)

Analysis shows that all three websites scored low on this function, with the French platform having the highest number of mobilization features, namely urgent alerts and action calendar that call for mobilization to demand the release of the group's jailed militants. In comparison, the Sisters of Afterlife's website contains no direct action features. A number of factors may accounts for these 
results. First, as a group that espouses a radical, albeit peaceful, collective action agenda, the JC is continually targeted by the state's various security apparatuses, which prevents it from posting sensitive information about members and membership or action plans that can be used against the group. Furthermore, despite the internet being the organization's sole public media outlet that has escaped the state's censorship, it is not accessible to all members, which limits its use for general and direct mobilization campaigns. Finally, the internet is usually used in parallel with other communication tools, such as mobile phones, fax machines, in addition to interpersonal communication. The internet tends to complement, rather than supplant the role of these media, especially when it comes to mobilizing members in offline action. The variations between the Arabic and French websites for this function can be attributed to the fact that the French platform addresses mainly the SMO's adherents in the diaspora, particularly in the two francophone countries of France and Belgium, who enjoy higher levels of freedoms and often stage public demonstrations to denounce the Moroccan state's repressive methods against the group. The absence of mobilization on the Sisters of Afterlife's website only confirms the low results scored by the website on most of the functions studied, reflecting its marginal status for the JC leaders.

\section{Discussion}

The advance of the internet has undoubtedly expanded the capacity of social movements to advance their causes at many levels. In the context of undemocratic countries like Morocco, where opportunities for oppositional social movements to participate in mainstream politics are minimal, the internet is opening new spheres of action and contestation that challenge dominant orders and discourses. The case of the JC shows that this SMO is successfully tapping into the internet's potential to resist state censorship and the campaign aimed at weakening the organization. Analysis has demonstrated that the JC websites are predominantly used to denounce state repressive measures, promote alternative interpretations of religion and politics, and enhance inter-group cohesiveness and unity. These websites have allowed the group to challenge the state's repression and 
censorship, and to communicate critical and alternative frames and interpretations of religion, social justice and collective identity to those promoted by the state. In a country where the king controls secular and religious powers, ${ }^{17}$ the JC's societal project promoted on the websites links religious authority to the capacity of the ruler to establish social and political justice, thus questioning the legitimacy of the king and monarchy. In doing so, the JC's websites contribute to building an antagonistic public sphere that opposes and resists the mainstream public sphere.

Although the internet's main characteristics have built-in potential and traits, this does not guarantee their successful exploitation by different social movements. The study has argued that the use of interactivity and networking on the websites contributes to micro-mobilization, and also to enhancing internal cohesion and bonding, rather than to building dialogic communication and solidarity online. In fact, the potential of the internet for collective action is strongly shaped by a political context peculiar to Morocco and the studied SMO. Thus, the JC websites are rarely used to support offline action directly, or to openly sustain online mobilization, such as benefiting from the potential of the internet to build networks of solidarity, recruit new members or collect funds. While this can be attributed to a variety of factors, repressive measures against the organization remain the primary reason explaining it. As such, notwithstanding the potential of the internet to empower contentious collective action, self-censorship exercised by the organization itself points out the limitations of technology as a tool of liberation, and shows that its potential is always embedded within local and transnational power relations.

Equally important, analysis has revealed that the appropriation of the web potential by the JC is equally shaped by the SMO's worldview, collective action strategy and tactics and stance on gender issue. The differences between the Arabic and French versions of the organization's website underlined above show how the web potential is customized to serve various types of users and mobilization tactics. More importantly, the organization's stance on gender relations and interpretation of the role of women in its political and societal project strongly inform both the design and content of the website of the women's 
chapter. The website's low interactivity, for instance, allows women little control over the information and communication flow on it. Similarly, its exclusive focus on identity frames reflects the role given to women in the long-term societal objective of the organization, which is restricted to the private sphere only.

Furthermore, the article has shown how the internet's main functions and features are customized to serve the JC's project and communication strategy. Given the centrality of identity issues in the ideology and action of the organization, the whole web potential is adapted to this purpose, whether at the level of networking, interactivity, web design or content. A main finding of the present article is that it illustrated that the chief function of the three websites studied is the reinforcement of cohesiveness of the group, its unity and collective consciousness. In so doing, the websites contribute to the mobilization of the group, since they provide actual and potential members with information, interactive space, symbols and frames necessary to sustain their resolve and commitment to collective action in the face of repression. These websites, however, remain closed and self-oriented. That is, they may be promoting 'agonistic politics associated with power and exclusion' (Dahlberg and Siapera, 2007,133 ) but they fail to draw on the potential of the internet to build alliances and networks capable of 'expanding the chains of equivalents between different struggles against oppression' (Hands, 2007, 91).

\section{Conclusion}

The article has examined the implications of the internet for Islamic-oriented social movements, focusing on the case of Moroccan SMO Justice and Charity. The article highlighted the role of various factors at the macro (societal), and meso (organization) levels that shape the potential of the medium and media practices of users at the micro level - particularly state repression and the absence of basic freedoms, and the strategy and ideology of the SMO marked by patriarchy and a focus on collective identity-building. Using social movement theory, in fact, allows

us to go beyond the narrow interpretation of the notion of 'mobilization' prevalent in the literature, which limits it to a mainly instrumental role of the internet in 
coordinating and building support for offline action. A social movement perspective extends the notion of 'mobilization' to a variety of practices and processes, which include, besides supporting offline action, the key processes of collective identity-building and micro-mobilization. As it is the case with all research projects, the present article has its own limitations, namely its concentration on the case of one organization. This is mitigated, however, by the fact the article can be considered an experimental effort, aimed at paving the way for new research directions on the subject, specifically by pointing out alternative perspectives, both theoretical and methodological, that can be used to better understand and analyse the implications of the internet for collective action in the context of Islamic societies.

\section{References}

Anderson, J.W. (2003) 'New media, new publics: reconfiguring the public sphere of Islam', Social Research 70(3): 887-906.

Anderson, J.W. (1999) 'The internet and Islam's new interpreters', in D.F. Eickelman and J.W. Anderson (eds.) New Media in the Muslim World: The Emerging Public Sphere, Bloomington: Indiana University Press, pp. 1-19.

Atton, C. (2004) An Alternative Internet, Edinburgh: Edinburgh University Press.

Belghazi, T. (2003) 'The politics of identity in the context of the Moroccan Islamist movement', available at http://74.125.155.132/scholar?q=cache:8Szrl5eTy5sJ:scholar.google.com/\&hl $=$ en\&as_sdt=2000 (accessed 6 July 2009).

Benford, R. and D. Snow (2000) 'Framing processes and social movements: an overview and assessment', Annual Review of Sociology 26: 611-39.

Bennett, W. (2003). 'Communicating global activism', Information, Communication and Society 6(2): 143-168.

Bunt, G. (2003) Islam in the Digital Age: E-jihad, Online Fatwas, and Cyber Islamic Environments, London: Pluto Press. 
Bunt, G. (2005) 'Defining Muslim interconnectivity', in M. Cooke and B.B. Lawrence (eds.) Muslim Networks from Hajj to Hip Hop, Chapel Hill: University of North Carolina Press, pp. 235-49.

Burbules, N. and T. Callister (2000). Watch IT: The Risks and Promises of Information Technology for Education, Boulder, CO: Westview Press.

Carpentier, N. (2002) 'Beyond the Virtual Binary ICTs as Tools for Bridging Cultural

Divisions'. Paper prepared for the digital divide working group at the 23rd Conference of the International Association of Media and Communication Research (IAMCR). Barcelona, 21-6 July.

Castells, M. (2004) The Power of Identity, Malden, MA: Blackwell.

Cavatorta, F. (2005) 'The international context of Morocco's stalled democratization', Democratization 12(4): 548-66.

Cavatorta, F. (2006) 'Civil society, Islamism and democratisation: the case of Morocco', Modern African Studies 44(2): 203-22.

Dahlberg, L. and E. Siapera (2007) Radical Democracy and the Internet: Interrogating Theory and Practice, New York: Palgrave Macmillan. Diani, M. (2001) 'Social movement networks: virtual and real', in F. Webster (ed.) Culture and Politics in the Information Age, New York: Routledge, pp. 117-28. Diani, M. and D. McAdam (2003) Social Movements and Networks: Relational Approaches to Collective Action, Oxford: Oxford University Press.

Downey, J. and N. Fenton (2003) 'New media, counter publicity and the public sphere', New Media \& Society 5(2): 185-202.

Downing, J. (2001) Radical Media: Rebellious Communication and Social Movements, Thousand Oaks, CA: SAGE.

Eickelman, D. and J. Anderson (2003) New Media in the Muslim World: The Emerging Public Sphere, Bloomington: Indiana University Press.

Fattah, M. (2006) Democratic Values in the Muslim World, Boulder, CO: Lynne Rienner.

Gamson, W. (1992) Talking Politics, New York: Cambridge University Press. 
Garrett, R.K. (2006) 'Protest in an information society: a review of literature on social movements and new ICTs, information', Communication \& Society 9(2): 202-24.

Gerodimos, R. (2008) 'Mobilizing young citizens in the UK: a content analysis of youth and issue websites', Information, Communication \& Society 11(7): 96488.

Gibson, R. and S. Ward (2000) 'A proposed methodology for studying the function and effectiveness of party and candidate websites', Social Science Computer Review 18(3): 301-19.

Habermas, J. (1981) The Theory of Communicative Action, London: Beacon Press. Hands, J. (2007) 'Between agonistic and deliberative politics: towards a radical edemocracy', in L. Dahlberg and E. Siapera (eds.) Radical Democracy and the Internet: Interrogating Theory and Practice, New York: Palgrave Macmillan, pp. 89-107.

Hoff, R. (2005) 'Dissident watch: Arash Sigarchi', Middle East Quarterly 12(4): 96.

Hunt, S.A. and R.D. Benford (2004) 'Collective identity, solidarity, and commitment', in D.A. Snow, S.A. Soule and H. Kriesi (eds.) The Blackwell Companion to Social Movements, Malden, MA: Blackwell, pp. 433-57.

Ibrahine, M. (2005) 'Morocco: internet making censorship obsolete', Arab Reform Bulletin 3(7): n.p.

Ibahrine, M. (2007) New Media and Neo-Islamism - New Media's Impact on the Political Culture in the Islamic World, Saarbrucken: VDM Verl. Muller.

Kahn, R. and D. Kellner (2004) 'New media and internet activism: from the "Battle of Seattle" to blogging', New Media \& Society 6: 87-95.

Khan, R. and D. Kellner (2007) 'Globalization, technopolitics, and radical democracy', in L. Dahlberg and E. Siapera (eds.) Radical Democracy and the Internet: Interrogating Theory and Practice, New York: Palgrave Macmillan, pp. 17-36.

Kitzinger, J. (2007) 'Framing and frame analysis', in E. Devereux (ed.) Media Studies: Key Issues and Debates, Los Angeles: SAGE. 
Kort, A. (2005) 'Dar al-cyber Islam: women, domestic violence, and the Islamic reformation on the world wide web', Journal of Muslim Minority Affairs 25(3): 363-83.

Laclau, E. and C. Mouffe (1985) Hegemony and Socialist Strategy, London: Verso. Lee, J.-S. (2000) 'Interactivity: A New Approach'. Paper presented at the 2000 Convention of the Association for Education in Journalism and Mass Communication. Phoenix, Arizona, 9-12 August.

Liu, Y. (2003) 'Developing a scale to measure the interactivity of websites', Journal of Advertising Research 43: 207-16.

McAdam, D. (1982) Political Process and the Development of Black Insurgency, 19301970, Chicago: University of Chicago Press.

McMillan, S. (2002) 'Exploring models of interactivity from multiple research traditions: users, documents and systems', in L. Lievrouw and S. Livingstone (eds.) The Handbook of the New Media: The Social Shaping and Consequences of ICTs, London: SAGE, pp. 163-82.

McMillan, S.J. and E.J. Downes (2000) 'Defining interactivity: a qualitative identification of key dimensions', New Media \& Society 2(2): 157-79.

Mouffe, C. (1999) 'Deliberative democracy or agonistic pluralism', Social Research 66(3): 745-58.

Ottaway, M. and M. Riley (2006) 'Morocco: from top down reform to democratic transition', Carnegie Endowment for International Peace Publications, available at http://www.carnegieendowment.org/publications/?fa=view\&id=18747.

Putnam, R. and K. Goss (2002) 'Introduction', in R. Putnam (ed.) Democracies in Flux: The Evolution of Social Capital in Contemporary Society, Oxford: Oxford University Press, pp. 3-21.

Putnam, R. and K. Goss (2002) 'Introduction', in R. Putnam (ed.) Democracies in Flux: The Evolution of Social Capital in Contemporary Society, Oxford: Oxford University Press, pp. 3-21.

Rafaeli, S. (1988) 'Interactivity: from new media to communication', in R.P. Hawkins, J.M. Wiemann and S. Pingree (eds.) Advancing Communication 
Science: Merging Mass and Interpersonal Process, Newbury Park, CA: SAGE, pp. 110-34.

Snow, D.A. (2004) 'Framing processes, ideology, and discursive fields', in D.A. Snow, S.A. Soule and H. Kriesi (eds.) The Blackwell Companion to Social Movements, Malden, MA: Blackwell, pp. 380-412.

Snow, D.A., B. Rochford, S.K. Worden and R.D. Benford (1986) 'Frame alignment processes, micromobilization and movement participation', American Sociological Review 51: 464-81.

Stein, L. (2009) 'Social movement web use in theory and practice: a content analysis of US movement websites', New Media \& Society 11(5): 749-77.

Stromer-Galley, J. (2000) 'On-line interaction and why candidates avoid it', Journal of Communication 50(4): 111-32.

Stromer-Galley, J. (2004) 'Interactivity-as-product and interactivity-as-process', Information Society 20(5): 391-4.

Sundar, S., S. Kalyanraman and J. Brown (2003) 'Explicating web site interactivity: impression formation effects in political campaign sites', Communication Research 30(1): 30-59.

Szuprowicz, B. (1995) Multimedia Networking, New York: McGraw-Hill/Thousand Oaks: SAGE.

Taylor, V. and N. Van Dyke (2004) “Get up, stand up': tactical repertoires of social movements', in D.A. Snow, S.A. Soule and H. Kriesi (eds.) The Blackwell Companion to Social Movements, Malden, MA: Blackwell, pp. 262-85.

Van Aelst, P. and S. Walgrave (2004) 'The role of the internet in shaping the antiglobalisation movement', in W. Van de Donk, B.D. Loader, P.G. Nixon and D. Rucht (eds.) Cyberprotest: New Media, Citizens, and Social Movements, London: Routledge, pp. 97-123.

Warnick, B. (2006) Rhetoric Online: Persuasion and Politics on the World Wide Web, New York: Peter Lang.

Weitzman, B. (2003) 'Islamism, Moroccan-style: the ideas of Sheikh Yassine', Middle East Quarterly, available at www.meforum.org/519/islamismmoroccan-style-the-ideas-of-sheikh (accessed 15 August 2008). 
Wiktorowicz, Q. (2004) 'Introduction', in Q. Wiktorowicz (ed.) Islamic Activism: A Social Movement Theory Approach, Bloomington: Indiana University Press, pp. 1-36.

Williams, R.H. (2004) 'The cultural contexts of collective action: constraints, opportunities, and the symbolic life of social movements', in D.A. Snow, S.A. Soule and H. Kriesi (eds.) The Blackwell Companion to Social Movements, Malden, MA: Blackwell, pp. 91-115. 


\section{Tables}

\begin{tabular}{l|lcc}
\hline \multicolumn{4}{l}{ Table 1. Core frames on websites } \\
\\
\hline Website & Injustice frames & Identity frames (\%) & Agency frame (\%) \\
& $(\%)$ & & \\
& & & 1 \\
JC Arabic & 64 & 35.15 & 10 \\
JC French & 55 & 34.13 & 0 \\
JC Women & 0 & 100.00 & \\
\hline
\end{tabular}

\section{Table 2. Website freshness}

\begin{tabular}{l|rr}
\hline \multicolumn{1}{c|}{ Website } & New items & Frequency of updates \\
& added & daily \\
JC Arabic & 165 & daily \\
JC French & 120 & More than week \\
Sisters of Afterlife & 13 & . \\
\hline
\end{tabular}




\begin{tabular}{l|ccc}
\hline \multicolumn{3}{l}{ Table 3. Detailed interactivity results } & \\
\hline Function & JC Arabic & JC French & JC Women \\
\hline User-to-content interactivity & 0 & 0 & 0 \\
Comment on article & 0 & 1 & 0 \\
Submit/contribute content & 0 & 0 & 0 \\
Contact author/contributor & & & \\
User-to-user/interpersonal interactivity & 1 & 0 & 0 \\
Synchronous chat & 1 & 0 & 1 \\
Forum/discussion board & 1 & 0 & 1 \\
Share article via email & 0 & 0 & 0 \\
Share via social media & & & \\
User-to-system interactivity & 1 & 0 & 0 \\
Audio/video content & 1 & 1 & 0 \\
Contact webmaster & 0 & 0 & 0 \\
Receive email newsletters & 0 & 0 & 0 \\
RSS & 1 & 0 & 0 \\
Add to favorites or as homepage & 1 & 0 & 0 \\
Download content & 0 & 0 & 0 \\
Website plan & 1 & 1 & 0 \\
Search field/archive & 0 & 0 & 0 \\
Polls & 0 & 0 & 0 \\
Register online & 5 & 3 & 2 \\
Total & & & \\
\hline
\end{tabular}

Note: $0=$ absent; $1=$ present

\section{Table 4. Interactivity result summary}

\begin{tabular}{l|cccc}
\hline Website & User/content/ & User/user/4 & User/system/ & score/15 \\
& 3 & & 8 & \\
\hline JC Arabic & 0 & 3 & 5 & 8 \\
JC French & 1 & 0 & 2 & 3 \\
JC women & 0 & 2 & 1 & 3 \\
\hline
\end{tabular}




\begin{tabular}{l|ccccccccc}
\hline \multicolumn{1}{l}{ Table 5. Direct mobilization features. } \\
\hline & Join & Vol. & Don. & Boy. & Pet. & Cal. & Aler & Email & Total \\
JC Arabic & 0 & 0 & 0 & 0 & 0 & 0 & 1 & 0 & 1 \\
JC French. & 0 & 0 & 0 & 0 & 1 & 1 & 1 & 0 & 3 \\
Sisters of Afterlife & 0 & 0 & 0 & 0 & 0 & 0 & 0 & 0 & 1 \\
\hline
\end{tabular}

\section{Notes:}

Vol. $=$ Volunteer; Don. $=$ donate; Boy. $=$ boycott; Pet. $=$ sign a petition; Cal. $=$ calendar for action.

$0=$ absent; 1 = present.

${ }^{1}$ Mohammed VI succeeded his father Hassan II on the throne in July 1999.

${ }^{2}$ The information provided by Alexa.com, though revealing, remains biased. This is because Alexa, like all similar traffic-ranking sites, measures site popularity only among users who have downloaded their web plug-ins or sidebars.

${ }^{3}$ Charity is a central Sufi concept in the thought of the JC and is composed of three notions: charitable relation with God, meaning the highest levels of faith; charitable behaviour with others; and charitable work, and refers to seeking perfection in work and duties (posted on the JC website, in 'methodic concepts 6, Charity').

${ }^{4}$ Posted on the JC website in the folder entitled 'who we are: identity, objectives and tools' (2009).

${ }^{5}$ See: www.aljamaa.net/ar/index/index.shtml (Arabic) and www.aljamaa.net/fr/index/ (French).

${ }^{6}$ Although a number of secular feminist groups launched their own websites in the past, they usually stopped being updated after a short time, which further brings out the ability of the JC to use the internet effectively.

${ }^{7}$ Each of these categories will be discussed in more detail below.

${ }^{8}$ See: www.aljamaa.net/ar/index/index.shtml (Arabic), www.aljamaa.net/fr/index/ (French), www.mouminate.net/ar/index/index.shtml (Sisters of Afterlife).

${ }^{9}$ The article was posted on 10 December 2008. All translations from Arabic are mine.

10 'Who we are: identity, objectives and tools', JC website, 2009.

${ }^{11}$ Posted on 15 December 2008.

${ }^{12}$ Posted on 11 December 2008.

${ }^{13}$ A town in the south of Morocco where the police brutally crushed local activists and residents who were protesting against unemployment and marginalization.

${ }^{14}$ The second Caliph in the Umayyad dynasty (661-751 AD).

${ }^{15}$ This is a highly dense and symbolic story in Islam about the Prophet and his companion, who will become later, after the death of Prophet Muhammad, the first caliph in Islam. 
${ }^{16}$ The objectives of the website and the JC women chapter is provided under the file name 'Who are we?' (www.mouminate.net/thema/1.htm).

${ }^{17}$ In addition to his status as the head of state, the king holds the title of 'Amir-AlMuminin' (Commander of the Faithful), which makes him the supreme religious authority in the country. 